\title{
LA INVESTIGACIÓN SOBRE EL CLERO REGULAR MASCULINO EN LA ESPAÑA MODERNA Y ALGUNAS PERSPECTIVAS DE DESARROLLO*
}

\author{
RESEARCH ON MALE REGULAR CLERGY IN MODERN SPAIN AND SOME \\ DEVELOPMENT PERSPECTIVES
}

\author{
PESQUISA SOBRE CLERO REGULAR MASCULINO NA ESPANHA \\ MODERNA E ALGUMAS PERSPECTIVAS DE DESENVOLVIMENTO
}

\author{
GUILLERMO NIEVA OCAMPO** \\ Consejo Nacional de Investigaciones Científicas y \\ Técnicas Universidad Nacional de Salta \\ DOI: https://doi.org/10.46553/EHE.22.1.2020.p35-52
}

Resumen

\begin{abstract}
El presente artículo aporta un breve recorrido por la historiografía modernista española, dedicada al clero regular, junto al desarrollo de algunas cuestiones actuales que ocupan a los historiadores en este campo. Además, se plantean algunas cuestiones que esperan ser estudiadas o que requieren de un mayor desarrollo. En conjunto, se quiere llamar la atención de la comunidad científica sobre un campo de investigación que merece una mayor atención dada la centralidad y peso del clero regular masculino en la sociedad española del Antiguo Régimen y la disponibilidad de una masa documental considerable que facilitaría su estudio.
\end{abstract}

\section{Palabras clave}

Clero regular - historiografía - Edad Moderna - España - archivos

\begin{abstract}
This paper provides a brief overview of Spanish modernist historiography, dedicated to the regular clergy, along with the development of some current issues that occupy historians in this field. In addition, it proposes some issues that await further study or that require further development. Overall, we want to draw the attention of the scientific community to a field of research that deserves greater attention given the centrality and weight of the male regular clergy in the Spanish society of the Ancien Régime and the availability of a considerable documentary mass that would facilitate their study.
\end{abstract}

\section{Keywords}

\footnotetext{
* Fecha de recepción del artículo: 27/4/19. Fecha de aceptación: 15/4/2020.

** Investigador independiente del CONICET, Código ORCID: 0000-0001-9610-7264. Dirección postal: Necochea 229, $3^{\circ}$ B, CP 4400, Salta, Argentina, e-mail: guillermohis@ yahoo.es
} 
Regular Clergy - Historiography - Modern Age - Spain - Archives

\section{Resumo}

Este artigo fornece uma breve visão geral da historiografia modernista espanhola, dedicada ao clero regular, juntamente com o desenvolvimento de algumas questões atuais que ocupam os historiadores nesse campo. Além disso, surgem algumas questões que aguardam estudo ou que requerem maior desenvolvimento. No total, o objetivo é chamar a atenção da comunidade científica para um campo de pesquisa que mereça maior atenção, dada a centralidade e o peso do clero regular masculino na sociedade espanhola do Antigo Regime e a disponibilidade de uma massa documental considerável que facilitaria seu estudo.

\section{Palavras-chave}

Clero regular - historiografía - Idade Moderna - Espanha - arquivos

Hasta mediados del siglo XX, con pocas excepciones, los estudios sobre el clero regular español habían sido realizados por los miembros de las mismas órdenes religiosas, la mayor de las veces con sentido acrítico y apologético. ${ }^{1}$ Quizás se puedan señalar las investigaciones realizadas por Vicente Beltrán de Heredia, para la reforma de los dominicos, y en mayor medida las de Fidel Lejarza y Ángel Uribe, sobre la reforma de los franciscanos en el siglo XV, como los estudios pioneros de carácter científico, respaldados con fuentes contrastadas. ${ }^{2}$ Entre estos, también podemos incluir los trabajos de Miguel Battlori, sobre los jesuitas expulsos, aparecidos en $1966 .^{3}$

Sin embargo, en el ámbito universitario español fue un amplio y estimulante estudio sobre el clero español durante el siglo XVII, realizado por Antonio Domínguez Ortiz en los años 70, el que tendría un mayor impacto y visibilidad. ${ }^{4}$ Un trabajo que, sin detenerse a exponer los presupuestos metodológicos que lo inspiraban, realizaba la primera historia social del clero español. Estudio señero, que inspiró la producción posterior y que hoy en día es considerado por muchos investigadores como el punto de partida de una renovación historiográfica que llega hasta la actualidad. ${ }^{5}$

De todos modos, se tendría que esperar a los años Ochenta para que la producción científica dedicada al clero regular aumentara. En buena medida, ese atraso se debía a los intereses contrastados que ocupaban a los equipos de investigación españoles. ${ }^{6}$ De hecho, durante los Setenta la historiografía española se interesó mayormente por los análisis demográficos y económicos, y, desde una perspectiva estrictamente social, por las minorías, por lo que el examen de los grupos privilegiados,

1 Aunque se debe reconocer el esfuerzo realizado a través de publicaciones periódicas promovidas por las mismas órdenes religiosas, como Archivo Ibero-Americano, revista científica publicada por los franciscanos a partir del año 1914. Ofrecen también un panorama historiográfico general sobre el clero regular español en la Edad Moderna EGIDO LÓPEZ, 2007; REY CASTELAO, 2007.

2 BELTRÁN DE HEREDIA, 1939; DE LEJARZA; URIBE, 1957.

3 BATLLORI, 1966.

4 DOMÍNGUEZ ORTIZ, 1970.

5 CORTÉS PEÑA, 1996

6 MORGADO GARCÍA, 2007, pp. 76-77. 
incluido el clero, quedó relegado, salvo en el caso de la Inquisición. Situación que se prologó en los primeros Ochenta, ya que los historiadores se interesaban mayormente por los estudios acerca de la burguesía, del comercio y del estado de las autonomías, coincidiendo esto con la incorporación de España a la Comunidad Europea ${ }^{7}$.

Sin embargo, justamente a mediados de los Ochenta comenzaron a publicarse las primeras monografías acerca de las rentas, la producción y la gestión económica de los enclaves conventuales. De hecho, los estudios de Mora Cañada (señorío Valldigna), de García Martín (San Benito de Sahagún), de Sánchez Meco (Sal Lorenzo de El Escorial) y de López Martínez (los regulares del reino de Sevilla), publicados entre 1985 y 1990, ofrecieron unas primeras síntesis generales, a partir del estudio de situaciones regionales o particulares, en la que, entre otras cuestiones, se rebatía, al menos para los ámbitos locales analizados en esas investigaciones, ese inmovilismo y la falta de racionalidad de la gestión de los emprendimientos económicos de los regulares, pensamiento que habían sostenido los ilustrados del siglo XVIII, que luego se convertiría en un tópico historiográfico difícil de erradicar. ${ }^{8}$ De hecho, las investigaciones mencionadas explican la profunda preocupación de los monjes por explotar racionalmente sus recursos económicos, en función de sus necesidades y de las fluctuaciones del mercado. Conclusiones semejantes a las que llegaba Ángela Atienza en 1993 al estudiar las explotaciones agrarias del clero regular aragonés. ${ }^{9}$ Según Atienza, el clero regular tiene una actitud totalmente distinta a la del clero secular, que vive de sus rentas sin preocuparse por crear o mejorar su patrimonio, puesto que sus miembros luchan por el engrandecimiento de su casa y por la mejora y crecimiento económico de su orden con el fin de aumentar su poder y presencia social. ${ }^{10}$

Estas primeras investigaciones, y otras que vinieron después, centradas en cuestiones económicas, en la posesión y gestión de recursos y en la evolución de las rentas conventuales estaban, básicamente, vinculadas al sesgo economicista de las narrativas explicativas de esas décadas y a las mismas características de los fondos eclesiásticas custodiados en los archivos españoles del Estado. ${ }^{11}$

Después de la desamortización de Mendizábal (1836-1837), la documentación de los archivos conventuales pasó al Archivo de la Delegación Provincial de Hacienda, donde se realizó una primera selección de documentos: los papeles referentes a la gestión del patrimonio de cada monasterio se separaron de otros cuyo contenido era considerado marginal (libros de profesiones, enterramientos, libros de acuerdo, etc.). Estos fondos se trasladaron a la sección de Clero del Archivo Histórico Nacional. Hubo excepciones: la documentación de

7 Algunas referencias bibliográficas sobre la producción modernista española durante esos años, centradas en las cuestiones señaladas, se pueden ver en GARCÍA CÁRCEL, 2001; ALBEROLA-ROMÁ, 1997.

8 A. MORA CAÑADA, 1986; A. L. LÓPEZ MARTÍNEZ, 1992; G. SÁNCHEZ MECO, 1985. El estudio historiográfico más completo sobre la producción científica acerca del clero regular realizada hasta finales de los años 90 es el de GARCÍA HERNÁN et al., 1995.

9 ATIENZA LÓPEZ, 1993.

10 Asunto que retoma en un artículo más reciente, de corte historiográfico: ATIENZA LÓPEZ, 2012.

11 En este sentido, un lugar destacado ocupan las investigaciones dedicadas a la expansión de la propiedad urbana en manos de los conventuales, que había alcanzado un protagonismo y visibilidad de primera magnitud a lo largo de los siglos modernos. Véase, NEGREDO DEL CERRO, 2012. Un ejemplo de este creciente y sostenido poderío económico lo brinda el caso del Convento dominico de San Esteban de Salamanca, MARTÍN MARTÍN, 1973, 1975. 
monasterios de patronato real como El Escorial o Nuestra Señora de Atocha se trasladó al Archivo de Palacio; y ciertos conventos femeninos como la Encarnación, las Descalzas Reales o las Comendadoras, conservaron sus fondos, puesto que los monasterios de monjas fueron desamortizados, pero no sufrieron exclaustración. De esa primera selección, los documentos desechados se perdieron o pasaron a manos particulares y una mínima parte la podemos encontrar en la sección de Manuscritos de la Biblioteca Nacional de Madrid. ${ }^{12}$

La documentación disponible en la sección de Clero de la Biblioteca Nacional se puede clasificar en tres grandes bloques: a) fuentes referidas a hacienda y administración, como los libros de tumbo o becerros, los apeos, las escrituras de arriendos, censos, juros, o volúmenes contables; b) documentación relativa al gobierno interno como constituciones, libros de profesiones, libros de elecciones y actas de capítulos generales, libros de acuerdo, libros de visitas; c) pleitos, origen de una abundante documentación se puede completar con la otros archivos.

Las fuentes indirectas tienen un carácter complementario y su localización es más variada. Los fondos disponibles se encuentran en diversos archivos: el General de Simancas, el Histórico Nacional, los Archivos Municipales, la Biblioteca Nacional, el archivo del ministerio de Asuntos Exteriores, el de la Real Chancillería de Valladolid, los diocesanos. En el Archivo General de Simancas las fuentes son de carácter fiscal por ejemplo, catálogo de juros -, legislativo - agrupa documentos relativos a las medias de la Corona y el Papado en relación con el clero regular - y judiciales -producidos en el curso de cualquier procedimiento judicial en el que participasen. En el Archivo Histórico Nacional hay importantes fondos en las secciones de Consejos Suprimidos y Hacienda. En los archivos municipales como el de la Villa, hay documentación de gobierno y hacienda municipal relacionada con los diferentes conventos. Los fondos de la Biblioteca Nacional de Madrid contienen manuscritos relativos a la vida de algún religioso o la historia de una ordena además de los volúmenes de las antiguas bibliotecas conventuales. En el Archivo del Ministerio de Asuntos Exteriores se puede consultar la documentación diplomática emanada de las relaciones entre la Corona y la Santa Sede. El Archivo de la Real Chancillería de Valladolid incluye la mayor parte de los pleitos. En los Archivos Diocesanos como el de Toledo se encuentran interesantes visitas pastorales.

La III reunión científica, organizada por la Asociación española de Historia Moderna, realizada en Canarias en el año 1994, fue un hito importante para los estudios eclesiásticos. En las actas de dicho congreso, tituladas Iglesia y sociedad en el Antiguo Régimen, se publicaron numerosos artículos de corte historiográfico y metodológico, ofreciendo una agenda científica para los investigadores posteriores en la materia. ${ }^{13}$ Allí, María Teresa Benito Aguado ofreció, a mi entender, una definición novedosa del clero, entendido como "un grupo interrelacionado, inserto en la estratificación social general, inserción derivada de la función social, de la persistencia de los vínculos familiares y de la relación que se poseían antes de pasar a formar parte del estamento eclesiástico". ${ }^{14} \mathrm{Si}$ bien la definición es deudora de una metodología estructuralista, imperante en aquellos años, ponía de manifiesto la emergencia y aceptación entre los investigadores de una concepción del clero como producto social, cuyo estudio, además,

12 BURÓN CASTRO, 1995; CABALLERO GARCÍA, 2005.

13 SUÁREZ GRIMÓN; MARTÍNEZ RUIZ; LOBO CABRERA 1995.

14 BENITO AGUADO, 1995. 
se debía historizar. Por otro lado, en el mismo dossier Teófanes Egido López publicaba un excelente artículo de corte sociológico y también psicológico, en el que intentaba caracterizar al clero regular masculino español en la Edad Moderna. ${ }^{15}$ Un artículo importante, puesto que es de los pocos que han intentado pintar, a grandes trazos, algunos aspectos específicos del mundo de los regulares: el espacio conventual, la conciencia del "estado de perfección", la importancia otorgada al silencio, el significado del hábito, etc. Cuestiones que, desgraciadamente, apenas han suscitado la atención de los especialistas en investigaciones posteriores. ${ }^{16}$

Y es que, así como sucedía con Teófanes Egido, quien había comenzado sus investigaciones indagando acerca de la expulsión de los jesuitas, numerosos investigadores, sin que estuvieran relacionados institucionalmente con otros, a partir de entonces habían comenzado a realizar indagaciones sobre nuevos aspectos de la historia del clero regular, que se continuaron durante la primera década de este siglo. En este sentido, Enrique Martínez Ruíz se encargó de reunir un grupo de investigadores, con quienes publicó en el año 2004 una obra de referencia, que si bien presenta un desarrollo interno desigual, es de consulta obligada. ${ }^{17}$

Hay que decir que en los últimos años el interés de los investigadores se ha centrado mayormente en los siguientes tópicos:

Para el siglo XVI, en la reforma de las órdenes religiosas y en el posterior desarrollo de la descalcez. En el primer caso, se trata de un tema que interesa también a los estudiosos del siglo XV y que de algún modo ha llevado a señalar como hito de inicio de los tiempos modernos, en el caso del mundo eclesiástico, no tanto al cisma luterano del siglo XVI, sino al Concilio de Constanza, a principios del siglo XV, motor de arranque de las experiencias reformistas en el ámbito de los regulares. ${ }^{18}$

A los ya clásicos estudios sobre la reforma de las órdenes religiosas realizados por Vicente Beltrán de Heredia y por José García Oro, ${ }^{19}$ para dominicos y franciscanos respectivamente, se han sumado los realizados por Miura Andrade, ${ }^{20}$ García Serrano, ${ }^{21}$ Olivera Serrano, ${ }^{22}$ Rojo Alique, ${ }^{23}$ Nieva Ocampo ${ }^{24}$ y, más recientemente, Juan Prieto Sayagués, ${ }^{25}$ quienes han vinculado la promoción de la reforma en los conventos mendicantes españoles, no tanto a un enfrentamiento interno entre dos concepciones de la vida conventual - que muchas veces ha sido identificada como una lucha de "buenos contra malos" - sino con un fenómeno íntimamente ligado a los vínculos que los religiosos tenían con agentes externos a la orden, es decir, al ejercicio del patrocinio de diferentes agentes: particularmente con miembros de los nuevos linajes de la nobleza

15 EGIDO LÓPEZ, 1995.

16 A pesar del enfático reclamo que el mismo Teófanes Egido había hecho al respecto, EGIDO LÓPEZ, 2007.

17 MARTÍNEZ RUIZ, 2004.

18 Sobre el cambio epocal que significó en el mundo de los regulares el Concilio de Constanza, véase MIXON, 2013.

19 GARCÍA ORO, 1979; 1993; 2005.

20 MIURA ANDRADES, 1998; 2014; 2015; 2016.

21 GARCÍA SERRANO, 2014

22 OLIVERA SERRANO, 2013; 2016.

23 ROJO ALIQUE, 2004; 2006; 2007.

24 NIEVA OCAMPO, 2009a; 2009b; 2016; 2015; 2012a; $2012 b$.

25 PRIETO SAYAGUÉS, 2015; 2016; 2017. 
castellana y con la misma corona. De allí las marchas y contramarchas y la violencia del proceso reformista, que concluyó recién a mediados del siglo XVI, ofreciendo el panorama de unas órdenes rotas, como en el caso de la familia franciscana, dividida en torno al régimen de vida elegido, entre conventuales y observantes, y sus respectivos desgajamientos descalzos y recoletos. En el caso de los dominicos se asiste, por su parte, a una solución similar, bajo la aparente ausencia de ruptura, que esconde el fracaso de una reforma, en la que se prefirió negociar la creación de nuevas provincias o la admisión de dos tipos de conventos y de regímenes de vida en una misma jurisdicción. Es decir, la existencia de conventos pequeños, pobres y marginales, cuyos frailes se dedicaron a la predicación en el ámbito rural castellano, junto a otros ricos, poblados y emplazados en grandes centros urbanos, cuya vida se centró en la formación de clérigos intelectuales, proclives a realizar una brillante carrera en las aulas universitarias, al servicio de la Corona o en los cuadros dirigentes de la iglesia española o de la misma orden. Por lo tanto, dos tipos de comunidades, con dos tipos de frailes, que evidenciaron sus discrepancias en varios momentos de crisis: Guerra de las Comunidades, conquista misional de México, implantación de estatutos de limpieza de sangre, actuación inquisitorial, etc.

Por otro lado, el estudio específico del desarrollo de la descalcez, sobre todo de la franciscana, tiene una larga historia, a partir de los trabajos de Fidel de Lejarza y Ángel Uribe, en los años Sesenta, que alcanzaron una cúspide, a nuestro juicio, con la excelente tesis doctoral realizada en el año 2005 Daniel Vaquerín Aparicio, que si bien estudia la descalcez durante el siglo XVIII, realiza una extensa, completa e instructiva introducción sobre el desarrollo precedente de ese movimiento, sobre la historia de sus líderes, sobre sus caracteres originales y sobre sus patronos y promotores. ${ }^{26}$ Análisis que permite corroborar, una vez más, que ese tipo de comunidades religiosas, pequeñas, rurales y apegadas a la espiritualidad del recogimiento, se desarrollaron al abrigo de potentados pertenecientes a la nobleza extremeña y andaluza, pero nunca fueron promovidas por la Corona. De hecho, el recurso a Roma y la oposición de Felipe II a su desarrollo - y de la Inquisición - sería una característica del movimiento durante el siglo XVI, que incluyó también a los recoletos. En este sentido, una excelente guía acerca del desarrollo del movimiento recoleto en distintas órdenes religiosas a lo largo del siglo XVI y XVII la encontramos en un reciente y completo artículo publicado por Ángel Martínez Cuestas, donde estudia su desarrollo histórico y sus características comunes, manifestada en distintas órdenes religiosas, ofreciendo una amplia referencia de la profusa bibliografía sobre el tema. ${ }^{27}$ Por su parte, la historia de los franciscanos conventuales y las consecuencias del proceso de confesionalización de Felipe II, es decir, su supresión, han sido magníficamente estudiadas por Gonzalo FernándezGallardo Jiménez. ${ }^{28}$ En la misma publicación Fernández-Gallardo considera que el apoyo dado por la Corona a los observantes franciscanos terminó por reducirlos a una estructura más al servicio de la Corona. De hecho, el proceso de confesionalización verificado durante el reinado de Felipe II puede ser considerado como un expediente totalizante en el ámbito del clero regular español.

El origen e implantación de nuevas comunidades religiosas, como es el caso de jesuitas y capuchinos. La proliferación de estudios sobre los jesuitas se debe a la labor promovida desde la propia orden, con publicaciones periódicos como Archivium

26 VAQUERÍN APARICIO, 2004.

27 MARTÍNEZ CUESTA, 2007.

28 FERNÁNDEZ-GALLARDO JIMÉNEZ, 1999. 
Societates Jesu, y a la existencia de una enorme masa documental, muy bien catalogada en los archivos españoles de Granada y Toledo, y en el Archivo de la Curia Generalicia, en Roma, el ARSI. A los estudios realizados por Enrique Giménez López, director y pilar fundamental del grupo de investigación alicantino que ha estudiado a la Compañía de Jesús en el Setecientos, ${ }^{29}$ se agregaron recientemente los trabajos de Burrieza Sánchez, que atienden particularmente a la cura pastoral y a la dirección espiritual desarrollada por los padres de la Compañía, así como a la fundación de sus colegios en el ámbito castellano. ${ }^{30}$ Burrieza también ha colaborado en una obra de síntesis, Los jesuitas en España y en el mundo hispánico, publicado por Marcial Pons en el año 2004, que ofrece una introducción general sobre el tema, con un amplio repertorio bibliográfico. También son interesantes los estudios realizados por Julián Lozano Navarro, acerca de los vínculos de poder tejidos por los jesuitas con las elites políticas españoles durante los siglos XVI y XVII, ${ }^{31}$ y los trabajos de Esther Jiménez Pablo, que complejiza lo expuesto por Lozano Navarro, introduciendo en sus estudios el tema de la continuas negociaciones entre los agentes el rey de España y los prepósitos generales de la Compañía, interesados por imponer las directrices papales por diversas vías y medios, a partir de la documentación vaticana y del ARSI. ${ }^{32}$

En el caso de los estudios sobre literatura espiritual, expresión de los movimientos reformistas del siglo XVI, a las investigaciones realizadas por Marcel Bataillón, Rodríguez Sanz y Melquíades Andrés, que permitieron identificar las distintas corrientes de espiritualidad correspondientes a cada familia religiosa, se han sumado nuevos estudios que exploran en el consumo de esa literatura vinculado al origen de la imprenta, al negocio del libro, a las características de las demanda a lo largo del siglo XVI y a la intervención de la corona mediante las expurgaciones ordenadas por la inquisición, tal como lo han presentado Rafael García Pérez. ${ }^{33}$ De hecho, Rafael García ha logrado identificar las distintas etapas en el desarrollo de esa producción a lo largo del siglo XVI, uniendo ello a las necesidades espirituales de las aristocracias andaluzas y extremeñas. ${ }^{34}$ Además, ha estudiado las características que asumen las bibliotecas conventuales, sobre todo las pertenecientes a los conventos descalzos franciscanos, advirtiendo que en el transito al siglo XVII esos conventos comienzan a producir su propia literatura para la formación de sus miembros. ${ }^{35}$ Este tipo de estudio ha permitido, además, conocer el funcionamiento de una provincia franciscana, a partir de la identificación de los centros de estudio y de las etapas de formación de sus miembros. ${ }^{36}$

Unido a lo anterior, un desarrollo particular han conocido los estudios de las corrientes de espiritualidad promovidas por las órdenes religiosas como andamiaje ideológico de facciones políticas que dominaron en la corte de la monarquía hispana. Estudio fascinante, realizado por el equipo que dirige el profesor Martínez Millán, y que ha permitido redefinir el alcance de la tratadística religiosa y también del papel del clero

29 Entre sus publicaciones más recientes, GIMÉNEZ LÓPEZ, 2008; 2013; 2014; 2017; 2017.

30 BURRIEZA SÁNCHEZ, 2009; 2010; 2010; 2015.

31 LOZANO NAVARRO, 2005; 2009; 2012; 2012; 2016.

32 JIMÉNEZ PABLO, 2014; 2016; 2016; 2017.

33 PÉREZ GARCÍA, 2005; 2006.

34 PEREZ GARCIA, 2009; 2011; 2016.

35 PÉREZ GARCÍA, 2005; 2009; 2012.

36 Un panorama general, con un amplio apartado bibliográfico sobre la literatura espiritual en la España del siglo XVII puede consultarse en SERÉS, 2003. 
regular en la historia política de la monarquía de los Austrias. ${ }^{37}$ Entre otras cuestiones, se ha podido identificar las distintas opciones políticas y programas propuestos en el ámbito cortesano desde el tramo final del reinado de los Reyes Católicos hasta el de Felipe IV, que concluye en 1665. Los religiosos aportaron el contenido doctrinal a los distintos programas, vinculado a la espiritualidad del recogimiento en la primera mitad del siglo XVI, a una espiritualidad más intelectual y dogmática, esgrimida sobre todo por los dominicos, que aportó la base ideológica del proceso de confesionalización promovido por Felipe II, y que, finalmente, dio paso en el siglo XVII a una espiritualidad propuesta por los jesuitas y descalzos, de carácter estoico, que reorientó a una reconciliación política entre la Monarquía hispana y la Santa Sede, protectora y promotora de los movimientos descalzos y de un nuevo tipo de actividad misional, de conquista de las almas por la predicación.

Y es que resulta evidente que el apoyo de la Corona al proceso reformista desde finales del siglo XV se trocó en una mayor integración de los religiosos en la corte real - entendida como el espacio y el sistema de integración de las elites políticas de esa amplia monarquía - sobre todo en el ámbito de la real capilla. ${ }^{38}$ De allí que otro de los temas que ha concitado la atención de los especialistas sea el servicio de los religiosos pertenecientes a distintas familias religiosas en la corte. De aquel fenómeno que Benoist Pierre ha denominado "Clero de corte". ${ }^{39}$ Esa amalgama entre servicio a Dios y servicio al rey que encontramos en esos clérigos, particularmente entre los confesores reales, personajes que, junto a los predicadores de la capilla, mayor atención han concitado, sobre todo en tiempos de los Austrias y especialmente en el siglo XVII. Sobre este asunto, María Amparo Pérez Arandia ha publicado recientemente un artículo historiográfico en el que da cuenta de este tema y de la gran vitalidad de este tipo de estudios. $^{40}$

De todos modos, a nuestro juicio, es notable el desconocimiento general que existe acerca de la historia de estos religiosos antes que ocuparon esos cargos oficiales en la corte. De hecho, existe la impresión general de haber avanzado enormemente en el estudio de la carrera política de esos personajes, pero, al mismo tiempo, de ignorar la vida religiosa y conventual de esos individuos, puesto que, en buena medida, queda aún por hacer la historia de las comunidades religiosas de las que procedieron. Sobre todo, en el caso de los confesores dominicos de los Austria, queda por hacer una historia de la Provincia de España de la Orden de Predicadores en la Edad Moderna y de los mismos

37 MARTÍNEZ MILLÁN, 1994; 1998; 2001; 2003a; 2003b; 2008; 2015a; 2015b; MARTÍNEZ MILLÁN, JIMÉNEZ PABLO, 2015.

38 GARCÍA GARCÍA; CARRERAS ARES, 2001; PIZARRO LLORENTE, 2005; NEGREDO DEL CERRO, 2006a; 2006b; NOGALES RINCÓN, 2009; JIMÉNEZ PABLO, 2014; SÁNCHEZ BELÉN, 2014.

39 «Le "clergé de cour" désignait principalement les membres de la Chapelle, mous le définissons de notre côté comme l'ensemble des ecclésiastiques prenant part à la curia regis pour y remplir, y recevoir ou y retirer une charge ou une mission, le plus souvent validée par un office, une commission et/ou une dignité s'exerçant soit dans le cadre de la Chapelle, soit dans celui du Conseil et/ou de ses prolongements administratifs [...] L'avantage de cette notion de «clergé de cour» est d'être globalisante et systématique : elle ne définit pas les ecclésiastiques de l'entourage royal uniquement par leur relation au roi (les «prélats du roi ») et donc par le jeu de la faveur, du don et du contre-don, ni seulement par le type d'activités [...] mais par la nature polymorphe du service et par le système institutionnel et socio-culturel dans lequel il s'inscrivait. La notion permet en outre d'étudier le centre sans négliger la périphérie », PIERRE, 2013.

40 LÓPEZ ARANDIA, 2015. 
conventos madrileños, cuya documentación espera para ser estudiada en los archivos del Estado y de la Orden para ser estudiada.

Otro aspecto novedoso es el estudio de las crónicas, escritas desde mediados del siglo XVI y a lo largo del siglo XVII. Consideradas como obras apologéticas y despreciadas tradicionalmente por los investigadores a causa de ello, han sido revalorizadas recientemente por algunos colegas, entre los que se encuentran a María Rosa Alabrús Iglesias, Ángela Atienza López, Federico Palomo, Emilio Callado Estela como escritos muy útiles para la creación de la identidad de las órdenes y de disciplinamiento de sus miembros. ${ }^{41}$ También como instrumentos de propaganda $a d$ extra, para promocionar las bondades de una comunidad religiosa y de sus miembros ante el resto de la sociedad. Pero las crónicas son también fuente de información, por la documentación que a veces se transcribe en ellas y también por los intereses específicos que movieron a su autor a componer esas historias en un cierto modo. ${ }^{42}$ Cuestión que debe tenerse en cuenta en cada caso, para valorar correctamente la calidad del aparato informativo que las compone.

Por su parte, Ángela Atienza López ha realizado una amplia investigación sobre el fenómeno de las fundaciones conventuales. Ha estudiado los vínculos de patrocinio entre diversos potentados y un enorme abanico de fundaciones conventuales, promovidas por motivos espirituales y también como expresión de poder. De hecho, en su libro, titulado Tiempos de conventos, identifica para España 1173 fundaciones conventuales realizadas en el siglo XVI, 900 en el siglo XVII y 140 en el siglo XVIII, lo cual la lleva a hablar de una verdadera España conventual en los tiempos modernos, ya que las fundaciones de los regulares eran visibles hasta en los poblados más pequeños, siendo numerosísimas en algunas de las ciudades más importantes del reino, como es el caso de Sevilla, donde solamente de los franciscanos había seis conventos. ${ }^{43}$ Se trata de un equipo de investigación que prioriza el análisis de la funcionalidad de los conventos y monasterios para las elites políticas españolas, si bien, últimamente, también se han interesado, acertadamente, en el estudio de los vínculos familiar que sostenían las vocaciones y carreras de los religiosos, con el fin de explicar la opción por el claustro como verdaderas empresas familiares. ${ }^{44}$ Cuestiones que ya había puesto en luz, entre otros, Antonio Irigoyen López, en sus estudios dedicados a las carreras de los miembros del clero secular, quien considera que, en el caso de los grandes dignatarios eclesiásticos, las relaciones familiares y el apoyo dado por los parientes constituían uno de los pilares de esas promociones, junto a la preparación académica. ${ }^{45}$

La situación de los regulares en el siglo XVIII y de la posterior exclaustración ha recibido un notable tratamiento. Justamente, Ángela Atienza ha publicado hace muy pocos años un artículo historiográfico, con abundantes entradas bibliográficas sobre el tema, al que remitimos. ${ }^{46}$ Sin embargo, en ese mismo artículo la autora pone en consideración un tema que, a nuestro criterio, merece contar con nuevas investigaciones monográficas, que permitan precisar e incluso revisar las actuales conclusiones, que la

41 ATIENZA LÓPEZ, 2012; ALABRÚS IGLESIAS, 2012; CALLADO ESTELA, 2012; PALOMO DEL BARRIO, 2013; 2014.

42 NIEVA OCAMPO, 2016.

43 ATIENZA LÓPEZ, 2008.

44 ATIENZA LÓPEZ; BETRÁN MOYA, 2017.

45 IRIGOYEN LÓPEZ, 2008; 2010.

46 ATIENZA LÓPEZ, 2012. 
misma autora sostiene allí. Me refiero al vínculo que se considera que existió entre el decaimiento de las fundaciones conventuales en el siglo XVIII con la así denominada "religiosidad de los ilustrados", que se habría manifestado, en el caso de los frailes, en el abandono de las obligaciones de los antiguos patronos hacia los conventos, así como un cierto consenso social acerca de la inutilidad de los regulares y de lo lesivo que para el bien público eran sus emprendimientos conventuales, desde un punto de vista económico. Situación que habrían preparado el ambiente propicio para la desamortización exclaustración que terminaría con los regulares en el siglo XIX. No obstante, a pesar que Atienza cite para ello las voces de los consejeros del rey, junto a la de alcaldes y miembros de los consejos urbanos, no queda claro que en el caso de estos últimos su hostilidad hacia los regulares no fuera más que la manifestación del deseo de apropiarse de unos bienes económicos apetecidos por un colectivo social que solamente podría tomar posesión de ellos si estos perdían su carácter inalienable. Por otra parte, dicha hostilidad generalizada hacia el clero regular queda opacada cuando no se ha valorado convenientemente la voz de campesinos, censualistas, inquilinos de propiedades urbanas y demás miembros menesterosos de aquellas sociedades. ${ }^{47}$

Por otra parte, no existió un verdadero proceso de descristianización en España ni tampoco en Francia- sino de una cierta revalorización del erasmismo entre los intelectuales. ${ }^{48}$ De todos modos, merece la pena estudiar con mayor detenimiento el proceso de adopción por parte de las élites españolas, comenzando por las correspondientes a la corte madrileña, de nuevas corrientes de espiritualidad provenientes de justamente de Francia y de Italia desde mediados del siglo XVII, convendrá identificar a los agentes que permitieron dicho proceso, comenzando por los jesuitas y por las nuevas congregaciones religiosas, como fue la del Oratorio, que desde entonces se implantaron en suelo español y desarrollaron una sostenida labor pastoral entre los laicos, mediante la traducción y publicación de las obras de escritores espirituales italianos y franceses, como San Francisco de Sales, por ejemplo, o con la creación de escuelas, centros de instrucción o cofradías, en el marco de su lucha contra el jansenismo y el quietismo. ${ }^{49}$ Pero sobre todo con la fundación de asociaciones que promovían la puesta en práctica de esa nueva espiritualidad, que privilegiaba la conquista de la perfección sin abandonar el estado laico, como las Escuelas de Cristo o las cofradías del Sagrado Corazón de Jesús, que impulsaban la práctica de la "religión de los pobres", como la ha denominado acertadamente Châtellier. ${ }^{50}$ Junto a la Congregación del Oratorio, cuyo estudio apenas ha llamado la atención de los especialistas, también se necesita desarrollar la investigación sobre otras congregaciones, como las vinculadas a Propaganda Fidei o aquellas dedicadas exclusivamente a la educación, como es el caso de los Padres Escolapios, que luego reemplazarían en buena medida a los jesuitas, no sólo en el ámbito educativo, sino incluso en el mismo confesionario regio, tal como se observa en el caso de Carlos IV.

47 Los distintos procesos desamortizadores de los bienes del clero regular y sus efectos, a partir de 1809, merecen también una mayor puntualización y actualización, que permitan explicar con mayor precisión algunos fenómenos particulares, como las matanzas de frailes madrileños y el asalto a algunos conventos en los célebres motines populares de julio de 1834. Véase al respecto, REVUELTA GONZÁLEZ, 1976; SALVADOR Y CONDE, 1991; BARRIO GOZALO, 2000.

48 SUIRE, 2013; DINET, 1993; ROSA, 1999; CALLAHAN, 1989.

49 MESTRE SANCHÍS, 1975; TELLECHEA IDÍGORAS, 1979; CALLADO ESTELA, 2011; 2015; JIMÉNEZ PABLO, 2015; NIEVA OCAMPO, 2019.

50 GARCÍA FUERTES, 1993; 2014; CHÂTELLIER, 2002; REVUELTA GONZÁLEZ, 2008, pp. 388391; HERRADÓN FIGUEROA, 2009; LABARGA, 2013. 
Hay familias religiosas que apenas son mencionadas en alguna obra general, a pesar de su evidente importancia y poder durante los siglos modernos. Tal es el caso de los dominicos. Lo poco que conocemos sobre ellos, y que merece ser destacado, se lo debemos al trabajo en solitario realizado por Emilio Callado Estela, que ha centrado su interés en los dominicos de Valencia durante el siglo XVII, ${ }^{51}$ y al conjunto de artículos y fuentes que con regularidad se publican en el anuario Archivo Dominicano, de la Provincia dominica de España.

Asimismo, falta investigar específicamente al clero regular madrileño, sobre todo por la notable influencia que esos religiosos ejercieron en las familias de las élites cortesanas, a raíz del control sobre el sistema educativo y en la economía del honor y del prestigio, que se tradujo en un mayor el peso inmobiliario y rentístico de dichas fundaciones, que de ser 4 en el año 1500 habían alcanzado el número de 73 a finales del siglo XVIII. ${ }^{52}$ Desde el punto de vista educativo, si bien existe un excelente estudio sobre el Colegio Imperial de los jesuitas, nada sabemos, por ejemplo, sobre los dominicos de Madrid, quienes tenían cinco conventos en la ciudad y, entre ellos, a uno de sus colegios más prestigioso, el de Santo Tomás. ${ }^{53}$ Por otro lado, si bien se ha realizado una somera descripción de la propiedad vinculada al clero regular de Madrid, faltan estudios más detallados al respecto, que den cuenta de la influencia ejercida por las fundaciones urbanas en el ámbito rural, desde el punto de vista económico, pero también pastoral, puesto que los religiosos también ejercían el patrocinio sobre parroquias de aldeas, derivando sus recursos hacia sus conventos y vinculándose también a una feligresía campesina. ${ }^{54}$ Estudios que deberían aplicarse también a otros ámbitos de la península.

Además de lo dicho, quedan aún sin explicar numerosas cuestiones específicas de la vida religiosa, que hasta el momento, poco o nada ha interesado a los académicos. ¿Por qué se entra en un convento? ¿Por qué se acepta una formación de ese tipo? ¿Qué elementos de esa vida, en algunos casos áspera y difícil, compensaban a un determinado religioso por aquello que había dejado? ¿Cómo afectó al gobierno de conventos y de provincias la aristocratización que sufrieron numerosas familias religiosas desde mediados del siglo XVII? ¿Cómo afectó ese proceso a la formación de los religiosos y a su oficio pastoral? ${ }^{55}$ Cuestiones aún pendientes, pero cuya resolución aportaría un notable salto cualitativo al conocimiento que tenemos sobre la sociedad española en la Edad Moderna.

51 CALLADO ESTELA 2002; 2002; 2005; 2007.

52 Una síntesis general sobre las familias religiosas afincadas en Madrid puede verse en PINTO CRESPO, 2001.

53 SIMÓN DÍAZ, 1952-1959.

54 Cuestiones señaladas también por NEGREDO DEL CERRO, 2012; MÉNDEZ SASTRE, 2001; MÉNDEZ SASTRE, 1993; MARTÍN DE LAS MULAS et al., 1991.

55 Ese proceso de aristocratización se puede seguir también en la implantación de los "estatutos de limpieza de sangre" en numerosas comunidades y en familias religiosas completas. Pero especialmente en la transformación que sufrieron los expedientes entre los siglos XVI y XVII, que pasaron de interrogar sobre el origen racial de los postulantes, a las averiguaciones sobre el oficio de sus progenitores o sobre su propia conducta anterior a la vida religiosa. NIEVA OCAMPO, 2017. 


\section{REFERENCIAS BIBLIOGRÁFICAS}

ALABRÚS IGLESIAS, Rosa María (coord.), La memoria escrita de los dominicos, Madrid, Arpegio, 2012.

ALBEROLA-ROMÁ, Armando (coord.), Diez años de historiografía modernista, Barcelona, Universidad Autónoma de Barcelona, 1997.

ATIENZA LÓPEZ, Ángela, Propiedad y señorío en Aragón: el clero regular entre la expansión y la crisis (1700-1835), Zaragoza, Institución Fernando el Católico, 1993.

ATIENZA LÓPEZ, Ángela, Tiempos de conventos. Una historia social de las fundaciones en la España Moderna, Madrid, Marcial Pons, 2008.

ATIENZA LÓPEZ, Ángela, "El clero regular mendicante frente al reformismo borbónico. Política, opinión y sociedad", Obradoiro de Historia Moderna, 21, 2012, pp. 191-217.

ATIENZA LÓPEZ, Ángela, "Las crónicas de las órdenes religiosas en la España Moderna. Construcciones culturales y militantes de época barroca", en Atienza López, Ángela (coord.), Iglesia memorable: crónicas, historias, escritos... a mayor gloria. Siglos XVI-XVIII, Madrid, Sílex, 2012, pp. 25-50.

ATIENZA LÓPEZ, Ángela; BETRÁN MOYA, José Luis, "Religiosos y religiosas. Lazos e intereses de familia en el seno del clero regular en el mundo hispánico de la Edad Moderna", en Rey Castelao, Ofelia; Cowen, Pablo (ed.), Familias en el Viejo y el Nuevo Mundo, La Plata, Universidad de La Plata, 2017.

BARRIO GOZALO, Maximiliano, "Reforma y supresión de los regulares en España al final del Antiguo Régimen (1759-1836)", Investigaciones históricas: Época moderna y contemporánea, 20, 2000, pp. 89-118.

BATLLORI, Manuel, La cultura hispano-italiana de los jesuitas expulsos: españoles, hispanoamericanos, filipinos, 1767-1814, Madrid, Gredos, 1966.

BELTRÁN DE HEREDIA, Vicente, O. P., Historia de la Reforma de la Provincia de España (1450-1550), Roma, Institutum Historicum FF. Praedicatorum, 1939.

BENITO AGUADO, María Teresa, "Clero e Historia social; nuevas perspectivas de estudio", en Suárez Grimón, Vicente J.; Martínez Ruiz, Enrique; Lobo Cabrera, Manuel (coord.), Iglesia y sociedad en el Antiguo Régimen. III Reunión Científica de Historia Moderna, vol. 1, Las Palmas, Universidad de Las Palmas de Gran Canaria, 1995, pp. 41-46.

BURÓN CASTRO, Taurino, "Los inventarios de desamortización. Recurso para el seguimiento del patrimonio documental", Boletín ANABAD, LXV, 1995, pp. 25-50.

BURRIEZA SÁNCHEZ, Javier, "Los jesuitas: de las postrimerías a la muerte ejemplar", Hispania Sacra ${ }^{\circ} 61$ (2009), pp. 513-544.

BURRIEZA SÁNCHEZ, Javier, "La estrategia y ministerio educativo en la antigua Compañía de Jesús (siglos XVI-XVIII)", en Beltrán Moya, Juan Luis (coord.), La Compañía de Jesús y su proyección mediática en el mundo hispánico durante la Edad Moderna, Madrid, Sílex, 2010, pp. 179-218.

BURRIEZA SÁNCHEZ, Javier, La compañía del padre Hoyos: contexto jesuítico y devoción al Sagrado Corazón de Jesús, Maliaño, Cantabria, Sal Terrae, 2010.

BURRIEZA SÁNCHEZ, Javier, "“"Hace mucho al caso tratar con personas experimentadas": los ámbitos femeninos de la Compañía de Jesús", en Burrieza Sánchez, Javier (ed.), El alma de las mujeres: ámbitos de espiritualidad femenina en la modernidad (siglos XVI-XVIII), Valladolid, Universidad de Valladolid, 2015, pp. 325-364.

BURRIEZA SÁNCHEZ, Javier, "Pedro de Calatayud, retrato de un misionero popular barroco en tiempos de las Luces", en Callado Estela, Emilio (ed.), De Rebus Ecclesiae. Aspectos de la historiografía eclesiástica sobre el siglo XVIII, Valencia, Institució Alfons el Magnànim Centre Valencia d'estudis i d'investigació, 2017, pp. 79-96.

CABALLERO GARCÍA, Antonio, "Desamortización y patrimonio documental: un ejemplo de tratamiento de archivos en el siglo XIX", Signo. Revista de Historia de la Cultura Escrita, 15, 2005, pp. 77-117.

CALLADO ESTELA, Emilio, "Los Dominicos Valencianos y su oposición a la santidad del "Paré Simó"”, Archivo Dominicano: Anuario, 23 (2002), pp. 307-317. 
CALLADO ESTELA, Emilio, Iglesia, poder y sociedad en la Valencia del siglo XVII: el pontificado de Fray Isidoro Aliaga (1612-1648), Valencia, Universidad de Valencia, 2002.

CALLADO ESTELA, Emilio, "Los colegios dominicanos de san Vicente Ferrer de Zaragoza y Barcelona", Escritos del Vedat, 35, 2005, pp. 169-194.

CALLADO ESTELA, Emilio, Por Dios y por el rey. El inquisidor general fray Juan Tomás de Rocabertí, Valencia, Institució Alfons el Magnànim, 2007.

CALLADO ESTELA, Emilio, "El oratorio de San Felipe Neri y la controversia sobre las comedias en la Valencia del siglo XVII", Hispania Sacra, 63, 2011, pp. 133-153.

CALLADO ESTELA, Emilio, "Historia y glorias dominicanas en la obra editorial de fray Juan Tomás de Rocabertí", en Alabrús Iglesias, Rosa M. (coord.), La memoria escrita de los dominicos, 2012, pp. 59-85.

CALLADO ESTELA, Emilio, "Origen, progreso y primeras tribulaciones del oratorio de San Felipe Neri en España. El caso valenciano", Libros de la Corte.es, Extra 3, 2015, pp. 51-72.

CALLAHAN, William J., Iglesia, poder y sociedad en España, 1750-1874, Hondarribia, Nerea, 1989.

CHÂTELLIER, Louis, La religión de los pobres. Europa en los siglos XVI-XIX y la formación del catolicismo moderno, Bilbao, Desclée de Brower, 2002.

CORTÉS PEÑA, Antonio L., "Domínguez Ortiz y la Historia social de la Iglesia", Manuscrits: Revista d'història moderna, 14, 1996, pp. 39-58.

NOGALES RINCÓN, David, La representación religiosa de la monarquía castellano-leonesa: la Capilla Real (1252-1504), tesis doctoral inédita, Madrid, Universidad Complutense de Madrid, 2009.

DE LEJARZA, Fidel; URIBE, Ángel, "Introducción a los orígenes de la Observancia en España. Las reformas de los siglos XIV y XV", Archivo Ibero-Americano, 17, 1957, número extraordinario.

DINET, Dominique, «La ferveur religieuse dans la France du XVIIF siècle », Revue d'Histoire Éclesiastique de France, LXXIX, 1993, pp. 275-299.

DOMÍNGUEZ ORTIZ, Antonio, La sociedad española en el siglo XVII, vol. II, El estamento eclesiástico, Madrid, CSIC, 1970.

EGIDO LÓPEZ, Teófanes, "Mentalidad colectiva del clero regular masculino", en Suárez Grimón, Vicente J.; Martínez Ruiz, Enrique; Lobo Cabrera, Manuel (coord.), Iglesia y sociedad en el Antiguo Régimen. III Reunión Científica de Historia Moderna, vol. 1, Las Palmas, Universidad de Las Palmas de Gran Canaria, 1995, pp. 555-571.

EGIDO LÓPEZ, Teófanes., "Historiografía del clero regular en la España Moderna", en Cortés Peña, Antonio L.; López-Guadalupe, Manuel L. (eds.). La iglesia española en la Edad Moderna. Balance historiográfico y perspectivas, Madrid, Abada, 2007, pp. 9-37.

EGIDO LÓPEZ, Teófanes, "La espiritualidad del siglo XVIII. Reflexión histórica e historiográfica", en Callado Estela, Emilio (ed.), De Rebus Ecclesiae. Aspectos de la historiografía eclesiástica sobre el siglo XVIII, Valencia, Institució Alfons el Magnànim Centre Valencia d'estudis i d'investigació, 2017, pp. 395-406.

FERNÁNDEZ-GALLARDO JIMÉNEZ, Gonzalo, La supresión de los franciscanos conventuales de España en el marco de la política religiosa de Felipe II, Madrid, Fundación Universitaria Española, 1999.

GARCÍA CÁRCEL, Ricardo, "La reciente historiografía modernista española", Chronica nova: Revista de historia moderna de la Universidad de Granada, 28, 2001, pp. 185-219.

GARCÍA FUERTES, Gema, "Sociabilidad religiosa y círculos de poder. Las Escuelas de Cristo, de Madrid y Barcelona, en la segunda mitad del siglo XVII", Pedralbes 13/2, 1993, pp. 319-328.

GARCÍA FUERTES, Gema, "Élites cortesanas y élites periféricas. La Santa Escuela de Cristo de Valencia en el siglo XVII", Estudis. Revista de Historia Moderna, 40, 2014, pp. 153-190.

GARCÍA GARCÍA, Bernardo J.; CARRERAS ARES, Juan José, La Capilla Real de los Austrias: música y ritual de corte en la Europa Moderna, Madrid: Fundación Carlos de Amberes, 2001.

GARCÍA HERNÁN, David; LEÓN SANZ, María Virginia; DE PAZZIS PI CORRALES, Magdalena.; PÉREZ BALTASAR, M. D, "Las órdenes religiosas en la España Moderna: 
dimensiones de la investigación histórica", en Suárez Grimón, Vicente J.; Martínez Ruiz, Enrique; Lobo Cabrera, Manuel (coord.), Iglesia y sociedad en el Antiguo Régimen. III Reunión Científica de Historia Moderna, vol. 1, Las Palmas, Universidad de Las Palmas de Gran Canaria, 1995, pp. 205-252.

GARCÍA ORO, José, "Conventualismo y observancia. La reforma de las órdenes religiosas en los siglos XV y XVI", en García-Villoslada, Ricardo (dir.), Historia de la Iglesia en España, vol. III: $1^{\circ}$ La Iglesia en los siglos XV-XVI, Madrid: BAC, 1979, pp. 211-350.

GARCÍA ORO, José, "Observantes, recoletos y descalzos. La monarquía católica y el reformismo religioso del siglo XVI", Actas del Congreso Internacional Sanjuanista, vol. II, Valladolid: Junta de Castilla y León, 1993, pp. 53-97.

GARCÍA ORO, José, "Reforma y reformas en la familia franciscana del Renacimiento", en Graña Cid, María del Mar (ed.), El Franciscanismo en la Península Ibérica. Balance y perspectivas, Barcelona, Asociación Hispánica de Estudios Franciscanos, 2005, pp. 235-255.

GARCÍA SERRANO, Francisco, "Del convento al palacio: los frailes y las oligarquías castellanas (siglos XIII-XIV)", en Beceiro Pita, Isabel (coord.), Poder, piedad y devoción: Castilla y su entorno (siglos XII-XV), Madrid, Sílex, 2014, pp. 77-102.

GIMÉNEZ LÓPEZ, Enrique, Misión en Roma: Floridablanca y la extinción de los jesuitas, Murcia, Universidad de Murcia, 2008.

GIMÉNEZ LÓPEZ, E., "Los Jesuitas valencianos y Felipe V", en Jiménez Estrella, Antonio; Lozano Navarro, Julián J. (ed.), Construyendo historia: estudios en torno a Juan Luis Castellano, Granada, Universidad de Granada, 2013, pp. 271-282.

GIMÉNEZ LÓPEZ, Enrique, "El destino de los colegios de la Compañía en Ciudad de México tras la expulsión de los jesuitas", Revista de historia moderna: Anales de la Universidad de Alicante, 32, 2014, pp. 271-284.

GIMÉNEZ LÓPEZ, Enrique, "Hacia la extinción de la Compañía de Jesús. El Monitorio de Parma y la Casa de Borbón", Estudis: Revista de historia moderna, 43, 2017, pp. 261-301.

GIMÉNEZ LÓPEZ, Enrique, La Compañía de Jesús, del exilio a la restauración: diez estudios, Alicante: Universidad de Alicante, Servicio de Publicaciones, 2017.

HERRADÓN FIGUEROA, María Antonia, "Reinaré en España. La devoción al Sagrado Corazón de Jesús", Revista de Dialectología y Tradiciones Populares, vol. LXIV, 2, 2009, pp. 193-218.

IRIGOYEN LÓPEZ, Antonio, "Un obispado para la familia: Francisco Verdín Molina, prelado de Guadalajara y Valladolid en la segunda mitad del siglo XVII", Historia mexicana, 58, 2008, pp. 557-594.

IRIGOYEN LÓPEZ, Antonio, "Aproximación historiográfica a las relaciones entre clero y familia en la España Moderna", en Soares da Cunha Mafalda, Hernández Franco Juan (coord.), Sociedade, família e poder na Península Ibérica = Sociedad, familia y poder en la Península Ibérica: elementos para uma historia comparativa = elementos para una historia comparada, Murcia, Universidad de Murcia, 2010, pp. 129-149.

JIMÉNEZ PABLO, Esther, La forja de una identidad: la Compañía de Jesús (1540-1640), Madrid, Polifemo, 2014.

JIMÉNEZ PABLO, Esther, "La espiritualidad en la Capilla Real de los Austrias como guía de la ortodoxia religiosa de la monarquía", Hortal Muñoz, José Eloy; Labrador Arroyo, Félix (dirs.), La Casa de Borgoña: la Casa del Rey de España, Lovaina, Leuven University Press, 2014, pp. 255-277.

JIMÉNEZ PABLO, Esther, "Oratorian spirituality in the Roman Court and its incidence on the pro-spanish faction", Libros de la Corte.es, Extra n ${ }^{\circ}$ 2, 2015, pp. 26-38.

JIMÉNEZ PABLO, Esther, "El P. Alfonso Salmerón S.I. y el gobierno de los colegios de Nápoles", Magallánica: revista de historia moderna, 4 (2016), pp. 56-78.

JIMÉNEZ PABLO, Esther, "La polémica instrucción del general Aquaviva a los confesores jesuitas en la corte de Madrid (1602)", en Rey Hazas, Antonio; Mariano de la Campa; Jiménez Pablo, Esther (coord.), La Corte del Barroco: Textos literarios, avisos, manuales de corte, etiqueta y oratoria, Madrid, Polifemo, 2016, pp. 713-735. 
JIMÉNEZ PABLO, Esther, "La santidad politizada en época moderna: estudios más recientes", Chronica nova: Revista de historia moderna de la Universidad de Granada, 43 (2017) pp. 1118.

LABARGA, Fermín, La Santa Escuela de Cristo, Madrid, Biblioteca de Autores Cristianos, 2013.

LÓPEZ ARANDIA, María Amparo, "Clérigos y cortesanos. Balance y nuevas perspectivas de investigación", en Rey Castelao, Ofelia; Suárez Golán, Fernando (ed.), Los vestidos de Clío. Métodos y tendencias recientes de la historiografía modernista española (1973-2013), Universidad de Santiago de Compostela, Santiago de Compostela, 2015, pp. 1129-1146.

LÓPEZ MARTÍNEZ, Antonio, La economía de las órdenes religiosas en el Antiguo Régimen, Sevilla, Diputación de Sevilla. Servicio de Archivo y Publicaciones, 1992.

LOZANO NAVARRO, Julián J., La Compañía de Jesús y el poder en la España de los Austrias, Madrid: Cátedra, 2005.

LOZANO NAVARRO, Julián. J., "Los generales de la Compañía de Jesús y el mundo de la política (siglos XVI-XVII)", Mágina, Revista Universitaria, 13, 2009, pp. 39-56.

LOZANO NAVARRO, Julián J., "Confesionario e influencia política: la Compañía de Jesús y la dirección espiritual de princesas y soberanas durante el barroco", en Martínez Millán, José; Pizarro Llorente, Henar; Jiménez Pablo, Esther (coord.), Los jesuitas: religión, política y educación (siglos XVI-XVIII), Vol. 1, Madrid, Polifemo, 2012, pp. 183-206.

LOZANO NAVARRO, Julián J., "Un personaje en tierra de nadie: Juan Everardo Nithard. Status social, Iglesia y política en la Europa barroca", en Soria Mesa, Enrique; Díaz Rodríguez, Antonio J. (coord.), Iglesia, poder y fortuna: clero y movilidad social en la España Moderna, Córdoba, Comares, 2012, pp. 29-50.

LOZANO NAVARRO, Julián J., "Dos embajadores del rey católico en la Roma del siglo XVII: Los cardenales Trivulzio y Nithard. Una perspectiva comparada", Chronica nova: Revista de historia moderna de la Universidad de Granada, 42, 2016, pp. 137-166.

MARTÍN DE LAS MULAS, Juan Francisco et al., "Religiosidad barroca y oligarquías urbanas la estrategia del clero regular madrileño", en Pinto Crespo, Virgilio; Madrazo Madrazo, Santos (coord.), Madrid en la época moderna, espacio, sociedad y cultura: coloquio celebrado los días 14 y 15 de diciembre de 1989, Madrid, Ediciones de la UAM, 1991, pp. 265-302.

MARTÍN MARTÍN, Teodoro, "La desamortización de bienes del Convento de San Esteban de Salamanca (I y II)", Ciencia Tomista, no 100 y 101, 1973, 1975, pp. 565-583 y pp. 71-90.

MARTÍNEZ CUESTA, Ángel, "El movimiento recoleto en los siglos XVI y XVII", Agustinos Recoletos: historia y espiritualidad, Madrid, Augustinus, 2007, pp. 50-103.

MARTÍNEZ MILLÁN, José, "Familia Real y grupos políticos: La princesa Doña Juana de Austria (1535-1573)", en Martínez Millán, José (dir.), La corte de Felipe II, Madrid, Alianza Editorial, 1994, pp. 73-106.

MARTÍNEZ MILLÁN, José, "Transformación y crisis de la Compañía de Jesús (1578-1594)", en Rurale, Flavio (coord.), I Religiosi a corte teologia, politica e diplomazia in antico regime: atti del seminario di studi Georgetown University a Villa "Le Balze", Fiesole, 20 ottobre 1995, Roma, Bulzoni, 1998, pp. 101-129.

MARTÍNEZ MILLÁN, José, "La capilla real: integración social y definición de la ortodoxia religiosa", Martínez Millán, José; Fernández Conti, Santiago (coord.), La monarquía de Felipe II: la Casa del Rey, Vol. 1, Madrid, Mapfre, 2001, pp. 517-540.

MARTÍNEZ MILLÁN, José, "La crisis del "partido castellano" y la transformación de la Monarquía Hispana en el cambio de reinado de Felipe II a Felipe III", Cuadernos de Historia Moderna. Anejos, 2, 2003a, pp. 11-38.

MARTÍNEZ MILLÁN, José, "Fazioni politiche e correnti spirituali nel servizio dell'imperatore Carlos V", en Cantú, Francesca (ed.), L'Italia di Carlo V. Guerra, religione e politica nel primo Cinquecento: atti del convegno internazionale di studi, Roma, 5-7 aprile 2001, Roma, Viella, 2003b, pp. 3-40.

MARTÍNEZ MILLÁN, José, "La adaptación problemática de la política y religiosidad hispana al Catolicismo Romano", en Martínez Millán, José (coord.), La monarquía de Felipe III, Vol. 1, Madrid, Mapfre, 2008, pp. 187-197. 
MARTÍNEZ MILLÁN, José, "El movimiento descalzo en los siglos XVI y XVII", Libros de la Corte.es, 3, 2015, pp. 101-120.

MARTÍNEZ MILLÁN, José, "Evolución política y religiosa de la Monarquía Hispana durante el siglo XVII", Carthaginensia: Revista de estudios e investigación, 31, 2015a, pp. 215-250.

MARTÍNEZ MILLÁN, José; JIMÉNEZ PABLO, Esther, "La capilla real: la transformación ideológica de la monarquía y su reflejo en la capilla real", en Martínez Millán, José; Hortal Muñoz, José Eloy (coord.), La corte de Felipe IV (1621-1665): reconfiguración de la Monarquía católica, Vol. 1, Madrid: Polifemo, 2015b, pp. 700-763.

MARTÍNEZ RUIZ, Enrique, El peso de la Iglesia: cuatro siglos de órdenes religiosas en España, Madrid, Actas, 2004.

MÉNDEZ SASTRE, Rafael, "La propiedad urbana del clero regular madrileño primeros resultados e hipótesis para una futura investigación", Serrano Martín, Eliseo; Sarasa Sánchez, Esteban (coord.), Señorío y feudalismo en la Península Ibérica (ss. XII-XIX), Vol. 3, Zaragoza, Institución Fernando el Católico, 1993, pp. 173-196.

MÉNDEZ SASTRE, Rafael, "La estructura conventual de la ciudad, siglos XII-XIX", en Virgilio Pinto Crespo (coord.), Madrid, Atlas histórico de la ciudad siglos IX-XIX, Madrid, Lunwerg Editores, 2001, pp. 312-323.

MESTRE SANCHÍS, Antonio, "Religión y cultura en el siglo XVIII", en García Villoslada, Ricardo (dir.), Historia de la Iglesia en España, t. IV, Madrid, Biblioteca de Autores Cristianos, 1979, pp. 582-743.

MIURA ANDRADES, José María, Frailes, monjas y conventos: las órdenes mendicantes y la sociedad sevillana bajomedieval, Sevilla, Diputación de Sevilla, 1998.

MIURA ANDRADES, José María, "Las reformas tempranas del franciscanismo castellano: eremitas, conventos y obediencias en la Andalucía de los siglos XIV y XV", Semata: Ciencias Sociais e Humanidades, 26, 2014, pp. 111-128.

MIURA ANDRADES, José María, "Servicio de Dios y provecho y salud de las almas": la predicación mendicante en el arzobispado de Sevilla durante la Baja Edad Media", Historia. Instituciones. Documentos, 42, 2015, pp. 241-273.

MIURA ANDRADES, José María, "La Provincia Bética de la Orden de Predicadores durante la Baja Edad Media. Los frailes", Revista de Humanidades 27, 2016, pp. 19-42.

MIXON, James, "Religious Life and Observant Reform in the Fifteenth Century", History Compass, 11/3, 2013, pp. 201-214.

MORA CAÑADA, Adela, Monjes y campesinos. El señorío de Valldigna en los siglos XVII y XVIII, Alicante, Instituto Juan Gil-Albert, de la Diputación Provincial de Alicante, y Centre d'Estudis i Investigacions Comarcals Alfons el Veil, de La Safor, 1986.

MORGADO GARCÍA, Antonio, "El clero en la España de los siglos XVI y XVII. Estado de la cuestión y últimas tendencias", Manuscrits: Revista d'història moderna, 25, 2007, pp. 75-100.

NEGREDO DEL CERRO, Fernando, "La capilla de palacio a principios del siglo XVII. Otras formas de poder en el alcázar madrileño", Studia Historica. Historia Moderna, 28, 2006a, pp. 63-86.

NEGREDO DEL CERRO, Fernando, Los predicadores de Felipe IV. Corte, intrigas y religión en la España del Siglo de Oro, Madrid, Actas, 2006b.

NEGREDO DEL CERRO, Fernando, "Presencia e impacto de las órdenes religiosas en el mundo urbano. Una visión para la Castilla Moderna", Revista de historiografía (RevHisto), 16, 2012, pp. 91-104.

NIEVA OCAMPO, Guillermo, "Dejarlo todo por Dios, es comprar el cielo: el voto de pobreza, la mendicidad y el asistencialismo en los conventos dominicos castellanos de la reforma", Hispania Sacra, vol. LXI, 2009a, pp. 423-446.

NIEVA OCAMPO, Guillermo, "Reformatio in membris: Conventualidad y resistencia a la reforma entre los dominicos de Castilla en el siglo XV", En la España Medieval, 32, 2009b, p. 299-344.

NIEVA OCAMPO, Guillermo, "La observancia dominica y la monarquía castellana: compromiso político y disciplinamiento social (1460-1550)", José Martínez Millán (coord.), La corte en Europa: política y religión (siglos XVI-XVIII), Vol. I., Madrid, Polifemo, 2012, pp. 513-561. 
NIEVA OCAMPO, Guillermo, "Monarquía y clero regular: Los dominicos de Castilla durante el reinado de Enrique III y la minoría de Juan II", Cuadernos de Historia de España, 85-86, 2012, pp. 525-541.

NIEVA OCAMPO, Guillermo, "El confesor del emperador: la actividad política de fray García de Loaysa y Mendoza al servicio de Carlos V (1522-1530)", Hispania. Revista española de historia, 75, 2015, pp. 641-668.

NIEVA OCAMPO, Guillermo, “«Virtud christiana es grande, loar la memoria de los defuntos»: historia de la Orden dominica y de su reforma en la Crónica de fray Juan de la Cruz O.P. (1567)", Tiempos Modernos: Revista electrónica de Historia Moderna, 31, 2016a, pp. 345-368.

NIEVA OCAMPO, Guillermo, "De la colaboración a la oposición: los dominicos durante los reinados de Juan II y Enrique IV (1419-1474)", Erasmo. Revista de Historia Bajomedieval y Moderna, 3, 2016b.

NIEVA OCAMPO, Guillermo, "De la raza a la conducta: informaciones de limpieza de sangre en los conventos dominicos de Castilla (ss. XVI-XVII)", e-Humanista/Conversos, 5, 2017.

NIEVA OCAMPO, Guillermo, "El gusto por los maestros de espiritualidad francesa en la corte española. Las biografías de Juana de Chantal”, en Martínez Millán, José; Sánchez Belén, Juan A.; Rivero Rodríguez, Manuel, Del enfrentamiento a la amistad. Influencias entre las Monarquías de Francia y España en los siglos XVII y XVIII, Madrid, Polifemo, 2019, pp. 619638.

OLIVERA SERRANO, César, "Devociones regias y proyectos políticos: los comienzos del monasterio de San Benito el Real de Valladolid (1390- 1430)", Anuario de estudios medievales, 43, 2, 2013, pp. 799-832.

OLIVERA SERRANO, César, "Felipa y Catalina de Láncaster: Religiosidad y relato historiográfico", Anuario de estudios medievales, 46, 2016, pp. 361-391.

PALOMO DEL BARRIO, Federico, "Cultura religiosa, comunicación y escritura en el mundo ibérico de la edad moderna”, en Serrano Martín, Eliseo (coord.), De la tierra al cielo: Líneas recientes de investigación en historia moderna, Zaragoza, Institución Fernando el Católico, 2013, pp. 53-88.

PALOMO DEL BARRIO, Federico, "Introducción. Clero y cultura escrita en el mundo ibérico de la Edad Moderna", Cuadernos de Historia Moderna. Anejos, 13, 2014, pp. 11-26.

PÉREZ GARCÍA, Rafael M., "La biblioteca del convento de San Antonio de Padua de Lora del Río: libros de autor franciscano (1646)", Hispania Sacra, 57, 2005, pp. 745-794.

PÉREZ GARCÍA, Rafael M., Sociología y lectura espiritual en la Castilla del Renacimiento, 1470-1560, Madrid, Fundación Universitaria Española, 2005.

PÉREZ GARCÍA, Rafael M., La imprenta y la literatura espiritual castellana en la España del Renacimiento, Madrid, Ediciones Trea, 2006.

PÉREZ GARCÍA, Rafael M., "Los libros franciscanos de la biblioteca del Convento de Santa María de la Paz en la Puebla de Alcocer (1646)", Revista de estudios extremeños, 65, 2009, pp. 751-782.

PÉREZ GARCÍA, Rafael M., "Formas interiores y exteriores de la religión en la Baja Andalucía del Renacimiento: espiritualidad franciscana y religiosidad popular", Hispania sacra, 61 (2009), pp. 587-620.

PÉREZ GARCÍA, Rafael M., "Espirituales, Cortes Señoriales y Linajes Nobiliarios. Construcción y desarrollo de climas sacro-espirituales de referencia social en la Andalucía de los siglos XVI y XVII", Historia y Genealogía, 1, 2011, pp. 133-153.

PÉREZ GARCÍA, Rafael M., "Entre el conflicto y la memoria devota. La cronística franciscana ante la crisis espiritual de la orden en la España del quinientos", en Atienza López, Ángela (coord.), Iglesia memorable: crónicas, historias, escritos ... a mayor gloria. Siglos XVI-XVIII, Madrid, Sílex, 2012, pp. 361-386.

PÉREZ GARCÍA, Rafael M., "Francisco de Osuna frente a Erasmo. El norte de los estados y la controversia dealogada acerca del matrimonio", en Vian Herrero, Ana M.; Vega Ramos, María José; Friedlein Roger (ed.), Diálogo y censura en el siglo XVI (España y Portugal), Frankfurt del Maine, Vervuert, 2016, pp. 229-250.

PIERRE, Benoît, La monarchie ecclésiale. Le clergé de cour en France à l'époque moderne, Paris, Champ Vallon, 2013. 
PINTO CRESPO, Virgilio, "La Iglesia, organización y presencia", en Pinto Crespo, Virgilio (coord.), Madrid, Atlas histórico de la ciudad siglos IX-XIX, Madrid, Lunwerg Editores, 2001, pp. 296-311

PIZARRO LLORENTE, Henar, "La capilla real, espacio de la lucha faccional", en Martínez Millán, José; Fernández Conti, Santiago (dirs.), La Monarquía de Felipe II, I, Madrid, Fundación MAPFRE, 2005, pp. 143-51.

PRIETO SAYAGUÉS, Juan A., "La función sociopolítica de los monasterios y conventos en las ciudades de Castilla durante los reinados de Juan II y Enrique IV (1406-1474)", Roda da Fortuna, 1-1, 2015, pp. 411-437.

PRIETO SAYAGUÉS, Juan A., "El acercamiento de la monarquía castellana a la Orden de los Predicadores durante el reinado de Juan II de Castilla (1406-1454)", En la España Medieval, 39, 2016, pp. 197-224.

PRIETO SAYAGUÉS, Juan A., "La clerecía regular ante los conflictos internos y guerras exteriores de la Corona de Castilla durante la Baja Edad Media”, En la España Medieval, 40, 2017, pp. 309-337.

REVUELTA GONZÁLEZ, Manuel, La exclaustración (1833-1840), Madrid, BAC, 1976.

REVUELTA GONZÁLEZ, Manuel, La Compañía de Jesús en la España Contemporánea: Tomo III, Palabras y fermento (1868-1912), Madrid, Universidad Comillas, 2008.

REY CASTELAO, Ofelia, "Las economías monásticas en la Edad Moderna: un estado de la cuestión de la historiografía reciente (1994-2006)", en Cortés Peña, Antonio L.; LópezGuadalupe, Manuel L. (eds.). La iglesia española en la Edad Moderna. Balance historiográfico y perspectivas, Madrid, Abada, 2007, pp. 179-221.

ROJO ALIQUE, Francisco, El convento de San Francisco de Valladolid en la Edad Media ( $h$. 1220-1518), Madrid, Universidad Autónoma de Madrid, 2004.

ROJO ALIQUE, Francisco, "Los franciscanos conventuales en Valladolid y Palencia (siglos XIII-XV)", en Fernández-Gallardo Jiménez, Gonzalo (coord.), Los Franciscanos Conventuales en España: actas del II Congreso Internacional sobre el Franciscanismo en la Península Ibérica, Barcelona, 30 de marzo - 1 de abril de 2005, Barcelona, Asociación Hispánica de Estudios Franciscanos, 2006, pp. 125-148.

ROJO ALIQUE, Francisco "Reforma religiosa, sociedad y política en la Baja Edad Media: el ejemplo de San Francisco de Palencia en el siglo XV", Hispania Sacra, 59, 2007, pp. 469-491. ROSA, Mario, Settecento religioso, Venecia, Marsilio, 1999.

SALVADOR Y CONDE, José, Historia de la Provincia Dominica de España, II, de 1800 a la exclaustración, Salamanca, Editorial San Esteban, 1991.

SÁNCHEZ BELÉN, Juan, "Eclesiásticos criollos en la capilla real de Palacio: una élite de poder en el reinado de Carlos II (1655-1700)", Revista de Indias, 74, 2014, pp. 423-452.

SÁNCHEZ MECO, Gregorio, El Escorial y la orden jerónima: análisis económico social de una comunidad religiosa, Madrid, Editorial Patrimonio Nacional, 1985.

SERÉS, Guillermo, La literatura espiritual del Siglo de Oro, Madrid, Ed. del Laberinto, 2003.

SIMÓN DÍAZ, José, Historia del Colegio Imperial de Madrid: del estudio de la villa al Instituto de San Isidro, años 1346-1955, Madrid, Consejo Superior de Investigaciones Científicas, 1992.

SUÁREZ GRIMÓN, Vicente J.; MARTÍNEZ RUIZ, Enrique; LOBO CABRERA, Manuel (coords.), Iglesia y sociedad en el Antiguo Régimen. III Reunión Científica de Historia Moderna, vol. 1, Las Palmas, Universidad de Las Palmas de Gran Canaria, 1995.

SUIRE, Éric, Pouvoir et religion en Europe, XVIe-XVIIIe siècle, Paris, Armand Colin, 2013.

TELLECHEA IDÍGORAS, José Ignacio, "Molinos y el quietismo español", en García Villoslada, Ricardo (dir.), Historia de la Iglesia en España, t. IV, Madrid, BAC, 1979, pp. 475521.

VAQUERÍN APARICIO, Daniel, Vida, espiritualidad y proyección social de los franciscanos descalzos en la España de la Ilustración, Madrid, Universidad Complutense de Madrid, 2004 [Tesis doctoral inédita]. 